\title{
Self-report as a valid measure of yawning in the laboratory
}

\author{
MONICA GRECO and RONALD BAENNINGER \\ Temple University, Philadelphia, Pennsylvania
}

\begin{abstract}
The validity of self-report for studying yawning in the laboratory was examined. Thirty undergraduate students were assigned to one of two groups. Both groups recorded their own yawns using an Esterline Angus Chart Recorder. One group was given complete privacy, and the other group was videotaped through a two-way mirror. The observed group accurately recorded yawn frequency, yawn duration, and interyawn interval. The unobserved group did not differ from the observed group in recorded yawn frequency. Yawn duration and frequency were uncorrelated, and there was no correlation between duration and interyawn interval. Self-report is a valid measure of yawning and may be one of the only ways to study yawns in the laboratory, because it removes any inhibition against yawning in public.
\end{abstract}

Yawning may be ubiquitous in several vertebrate classes (Dumpert, 1921), but until recently it has not been the subject of much rigorous study. In humans, yawns have been observed as early as 5 min after birth (Blanton, 1917) and occur throughout the life span (Gesell, 1928; TaylorJones, 1927). Charles Darwin (1873/1965) described yawning as an act of deep inspiration with the mouth opened wide, followed by a forceful expiration simultaneously accompanied by the rapid closing of the mouth and a strong contraction of skeletal muscle groups. The stereotyped and repetitive nature of yawning has led to the suggestion that it is a fixed action pattern released by the sight of a yawning person or the mere thought of a yawn (Provine, 1986).

One aspect of yawning that has interested psychologists is its "infectious" nature. Moore (1942) reported that trained yawners could stimulate others to yawn and that motion pictures of a yawn initiated yawns in experimental subjects. Provine's (1986) subjects reported that their yawning frequency increased while observing others yawn, and also while reading or thinking about yawning. In contrast, Baenninger (1987) found that college students did not yawn while being observed in the laboratory whether they were observing another student live or on a TV monitor. Also, students who read a passage concerning yawning did not yawn more than those who read about scratching or daydreaming (Baenninger \& Greco, 1988). This absence of infectious yawning can be explained by hypothesizing that subjects actively inhibit yawns while being observed alone in a laboratory. Subjects are likely to experience anxiety about being observed by people who may be evaluating them. Alternatively, they may consider overt yawning in the presence of others to be rude. Yawning in the presence of others certainly

Address correspondence to Monica Greco, Department of Psychology, Temple University, Philadelphia, PA 19122. occurs (Baenninger, 1987), but may require some social support from peers (e.g., yawning during lectures).

In any event, a method of recording naturally occurring yawns must be devised before antecedents and consequences of yawning can be studied in the laboratory. Provine (1986) reported that when subjects were placed in a room by themselves and told to record their own yawns, yawning did take place, making possible the determination of the frequency and the duration of yawns, as well as the interval between yawns. This technique is not objective, by definition, since the subjects may not report their yawns accurately. The present study was an attempt to determine the validity of such self-reports.

\section{METHOD}

\section{Subjects}

Thirty undergraduate students from introductory psychology were assigned to one of two groups. Subjects in one group reported their own yawns, replicating the procedure described by Provine (1986); subjects in the other group reported their yawns, but were also monitored by a hidden video camera.

\section{Design and Procedure}

Each subject in the unobserved group was seated in a comfortable armchair and read the following instructions:

You are a participant in a study of the naturally occurring frequency and duration of yawns. In this experiment you will be recording your own yawning behavior. Yawning is easy. It is important that you relax and do not force yawns. It will be unnecessary; most people can yawn by just thinking about it. When you start to yawn, push down the button on the box in front of you. Consider the yawn to start when you begin to inhale. Consider the yawn to end when you finish exhaling. Keep the button depressed for the duration of the yawn. You will record the duration of each yawn for $15 \mathrm{~min}$. It is important to record your yawns as accurately as possible because, other than the responses you record, you will not be observed in any other way. You will have complete privacy. I will now demonstrate how to respond to a yawn. (The experimenter yawns and depresses the button as instructed above.) Think about yawning and you can produce a real yawn. Do you have any questions? After I leave the room, relax and think about yawning throughout the ses- 
sion and record your yawns as they occur. You will be notified when time is up.

When the subject depressed the button in response to a yawn, his/her responses were recorded by an Esterline Angus Chart Recorder driven at $2.5 \mathrm{~mm} / \mathrm{sec}$. After the subject produced his/her third yawn, the chart recorder was turned on and yawns were recorded for $15 \mathrm{~min}$. If a subject did not yawn within the first $5 \mathrm{~min}$, the recorder was turned on and $15 \mathrm{~min}$ of activity was recorded. Yawn duration was the time the subject kept the button depressed. The time from the onset of one yawn to the onset of the next was the interyawn interval.

The subjects in the observed group received the same treatment except that the assurance of complete privacy was deleted from their instructions, and they were videotaped through a small opening in a curtain covering a two-way mirror

\section{RESULTS}

In the group that was not observed by the video camera, 12 of the 15 subjects yawned at least once, and 1 yawned 22 times. The overall rate of yawning was 0.49 yawns per person per minute. In the videotaped group, 11 of the 15 subjects yawned at least once, and 1 yawned 13 times (a rate of 0.34 yawns per person per minute). The major results are shown in Table 1 . There was no significant difference between the number of yawns reported and the number of yawns observed in the videotaped group $[t(14)$ $=1.0, p>.30$ ]. Subjects in the videotaped group were accurate, with the exception of 1 who reported 6 yawns, whereas the video record showed only 4 . There was no significant difference between the duration of yawns recorded by the subjects in the videotaped group and the duration recorded on the videotape $[t(14)=.01$, $p>$.90]. The videotaped group did not differ from the unobserved group in the number of yawns reported [ $t(28)$ $=1.00, p>.20$ ]. Frequency of yawns and their duration were uncorrelated in both groups, and there was no correlation between duration and interyawn interval.

A contrast analysis of the distribution of yawns over the 15-min recording session revealed a linear trend in the frequency of yawns. The greatest number of yawns occurred in the first $5 \mathrm{~min}$. Yawn frequency decreased during minutes 6 to 10 . The last $5 \mathrm{~min}$ of the session yielded the lowest frequency of yawns $[F(1,58)=12.747$, $p<.001]$.

Table 1

Mean Yawn Frequency, Duration, and Interyawn Interval (in sec) for Observed and Unobserved Subjects

\begin{tabular}{lccc}
\hline Group & Frequency & Duration & Interyawn Interval \\
\hline Observed & & & \\
Objective & 5.07 & $\dot{4} .55$ & 96.29 \\
Subjective & 5.20 & 4.49 & 96.25 \\
Unobserved & 7.33 & 4.64 & 59.84 \\
\hline
\end{tabular}

Since the videotaped group and the unobserved group did not differ in the number of yawns they reported, the results of these two groups were combined and compared with the results Provine (1986) reported. The mean yawn duration Provine reported is significantly higher than the duration we found $[t(55)=2.49, p<.01]$, and the mean yawn frequency reported by Provine is significantly greater than the frequency we observed $[t(55)=2.512$, $p<.01]$. However, there was no significant difference between the interyawn intervals in the two studies.

\section{DISCUSSION}

Self-report appears to be a valid measure of yawning frequency, duration, and timing in that self-reports did not differ significantly from videotaped records. No relationships were found between the frequency, duration, and timing of yawns. Subjects who yawned infrequently did not appear to compensate by yawning for longer durations, and a high frequency of yawning was not associated with shorter intervals between yawns. The relative independence of these measures suggests that our subjects did not have any kind of "yawning time" distributed according to some lawful temporal pattern.

The downward trend of yawn frequency suggests that subjects may have been yawning in response to instruction rather than boredom. Since the subjects had been instructed to think about yawning, the waning that we found may have resulted because they stopped thinking about yawning as time passed. If their yawning had been a response to boredom, we would have found an increase in yawning frequency over time. In any event, our results confirm the contention that thinking about yawning is sufficient to produce yawning in a laboratory situation. It can also be concluded that self-report is a valid measure of yawning, despite the fact that it violates the basic maxim of objective science, namely that data must be public. In fact, self-report may be one of the only ways to observe yawns in the laboratory because it removes any inhibition against yawning in public.

\section{REFERENCES}

BAENNINGER, R. (1987). Some comparative aspects of yawning in Betta splendens, Homo sapiens, Panthera leo, and Papio sphinx. Journal of Comparative Psychology, 101, 349-354.

Baenninger, R., \& Greco, M. (1988, November). Yawning and arousal. Paper presented at 29th Meeting of the Psychonomic Society, Chicago.

Blanton, M. G. (1917). The behavior of the human infant during the first 30 days of life. Psychological Review, 24, 456-483.

DARWIN, C. (1965). Expression of emotions in animals and man. Chicago: University of Chicago Press. (Original work published 1873)

DumperT, V. (1921). Zur Kenntnis des Wesens und der Physiologischen Bedeutung des Gahnens. Journal für Psychologie und Neurologie, 27, 82-95.

GeSELL, A. (1928). The mental growth of the pre-school child. New York: Macmillan.

MOORE, J. E. (1942). Some psychological aspects of yawning. Journal of General Psychology, 27, 289-294.

Provine, R. R. (1986). Yawning as a stereotyped action pattern and releasing stimulus. Ethology, 72, 109-122.

TAYLOR-JONES, L. (1927). A study of behavior in the newborn. American Journal of Medical Science, 174, 357-362.

(Manuscript received May 17, 1988.) 